\title{
Electron Microscopy of Gold Soldered Joints
}

\author{
M. KAMAL EL-EBRASHI, KAMAL ASGAR, and W. C. BIGELOW \\ University of Michigan, School of Dentistry, Ann Arbor, Michigan
}

\begin{abstract}
Electron photomicrographs were taken to examine and compare the structure of the properly heated soldered joints with that of the overheated joints. No diffusion of the solder was observed in the former group and considerable diffusion took place in the latter group. Pronounced oxide formation, microporosity, and alloying with the parent alloy were observed in the overheated joints.
\end{abstract}

Dental soldering procedures have been developed in a rather empirical manner on the basis of soldering or brazing practices used in the jeweler's trade. Soldering may be defined as the joining of two pieces of metal or alloy by a solder, ${ }^{1}$ usually a low-fusing alloy, which is capable of wetting ${ }^{2}$ the parent metal. The structure of the two parts should not be altered by temperatures employed. The procedure involves melting of the solder alloy and flowing of the molten solder by capillary action between and around the adjacent heated, but unfused, parts to be joined. ${ }^{3-5}$ Theoretically, there should be no fusion of the parts by the solder. ${ }^{6}$

The purpose of this investigation was to examine and compare the ultrastructure of what has been assumed to be the "properly heated" soldered joint with that of the "overheated" joint. The gold alloys, solders, and soldering investments selected were representative of those materials commonly used in dental practice.

Electron photomicrographs of sections made of two different soldered joints made it possible to appraise critically the gold-solder interface, gas inclusions, solder pits at or near the interface, microporosity, diffusion between the parent alloy and the solder, as well as oxide formation.

This investigation was partially supported by USPHS Research Grant DE02017 from the National Institute of Dental Research, National Institutes of Health, Bethesda, Md.

Presented at the 44th General Meeting of the IADR at Miami, Fla., March 1966.

Received for publication August 26, 1966.

\section{Materials and Methods}

A typical Type III dental gold casting alloy* used for construction of inlays and fixed crown and bridge restorations was the parent alloy. The melting range of this alloy is 1,650 to $1,755 \mathrm{~F}$, and it has a Brinell hardness of No. 120 .

The soldert used has a melting range between 1,420 and $1,490 \mathrm{~F}$ and meets the colormatching and fluidity requirements for the parent alloy. Table 1 gives the typical composition of the parent alloy and the solder.

Soldering investment was used to surround the gold sections to be soldered. The common binder used in soldering investments is calcium sulfate.

Soldering Procedure.-Several plates of the parent gold casting alloys were cut in half, and rejoined by a hard, sticky wax. The assembled components were surrounded with soldering investment, with only the waxed joint being left exposed. After setting of the investment, the wax was removed with boiling water. The portion to be soldered was left exposed and free from investment to permit removal of the wax and to allow effective heating during the procedure.

The soldered joints were grouped according to the extent heated. Those joints in the first group were formed under "proper" heating conditions. The solder was melted by use of a gas blowpipe and was held in the molten stage for less than two seconds. In the second group, the parent metals and the solder were overheated by holding the oxyacetylene flame on the solder assembly for ten seconds after the solder was molten. All other factors involved remained the same.

Five samples of each group were made. Since the structure of all the samples within each group was consistent, it was decided

* Ney Oro B-2, J. M. Ney Co., Hartford, Conn. (Certified by the American Dental Association, Specification No. 5).

† Ney 650 Solder, J. M. Ney Co., Hartford, Conn. 

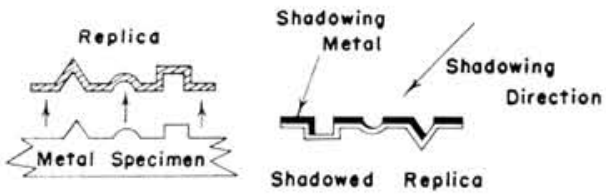

FIG 1,-Single-stage replica.

that no additional information could be obtained by increasing the number of samples.

The general principles of soldering, including maintenance of the cleanliness of the parts to be soldered, retention of the small gap between them, application of sufficient flux to cover the joint, and the use of a minimum amount of solder, were observed.

After the soldering operation was completed, the assembly was left to cool for approximately five minutes before quenching. Then pickling was accomplished by heating the soldered gold specimens in clean $50 \%$ sulfuric acid.

Mounting the Specimens and MetalloGRAPHIC POLISHING.-The gold soldered specimens were mounted in a resorcinol resin

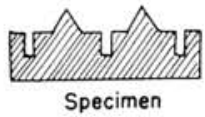

a

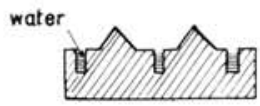

c

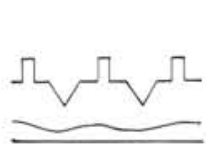

e

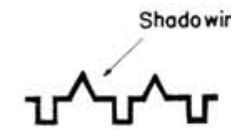

9

FIG 2.-Double-stage replica for rough, porous surfaces: $a$, specimen surface; $b$, specimen in water; $c$, partially dry specimen showing water nearly filling the pores; $d$, collodion film backed with gelatin applied to the specimen; $e$, backed collodion impression separated from the specimen: $f$, preliminary impression coated with carbon; $g$, final replica.

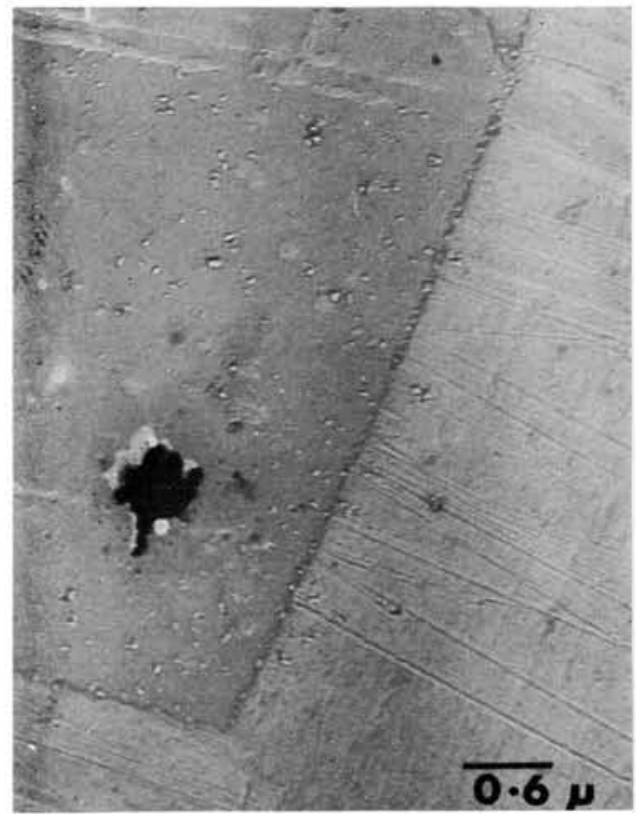

FIG 3.-Properly heated gold-solder interface, showing no diffusion. Note the solder pit (orig $\operatorname{mag} \times 33,000)$.

wood adhesive.* Acrylic resin was not used because it is attacked by acetone, which was used later in the electron microscopy replica technics. The specimens were polished by use of a standard metallographic procedure. In the last stages, a magnesium oxide replaced alumina to achieve a better polish, since $\mathrm{MgO}$ produced small scratches.

Specimens were lightly etched by swabbing their surfaces with the Jewett-Wise reagent ${ }^{-9}(10 \%$ potassium cyanide plus $10 \%$ ammonium persulfate in distilled water). All specimens were repolished on the last wheel and reetched for 15 seconds.

Replicas and SHadowing.-Both onestage and two-stage replicas were used (Fig 1, $2)$. A copper grid was used to achieve easier location of the interface.

\section{Results}

Properly Heated Gold Soldered Joint. - The gold-solder interface was examined at a magnification of $\times 24,000$. No diffusion occurred along this interface (Fig 3, 4).

Scratches shown in Figure 3 went across the softer parent gold alloy and stopped at the junction between the solder and the gold

\footnotetext{
* Bakelite boat resin, Fischer Scientific Co., Detroit.
} Mich. 

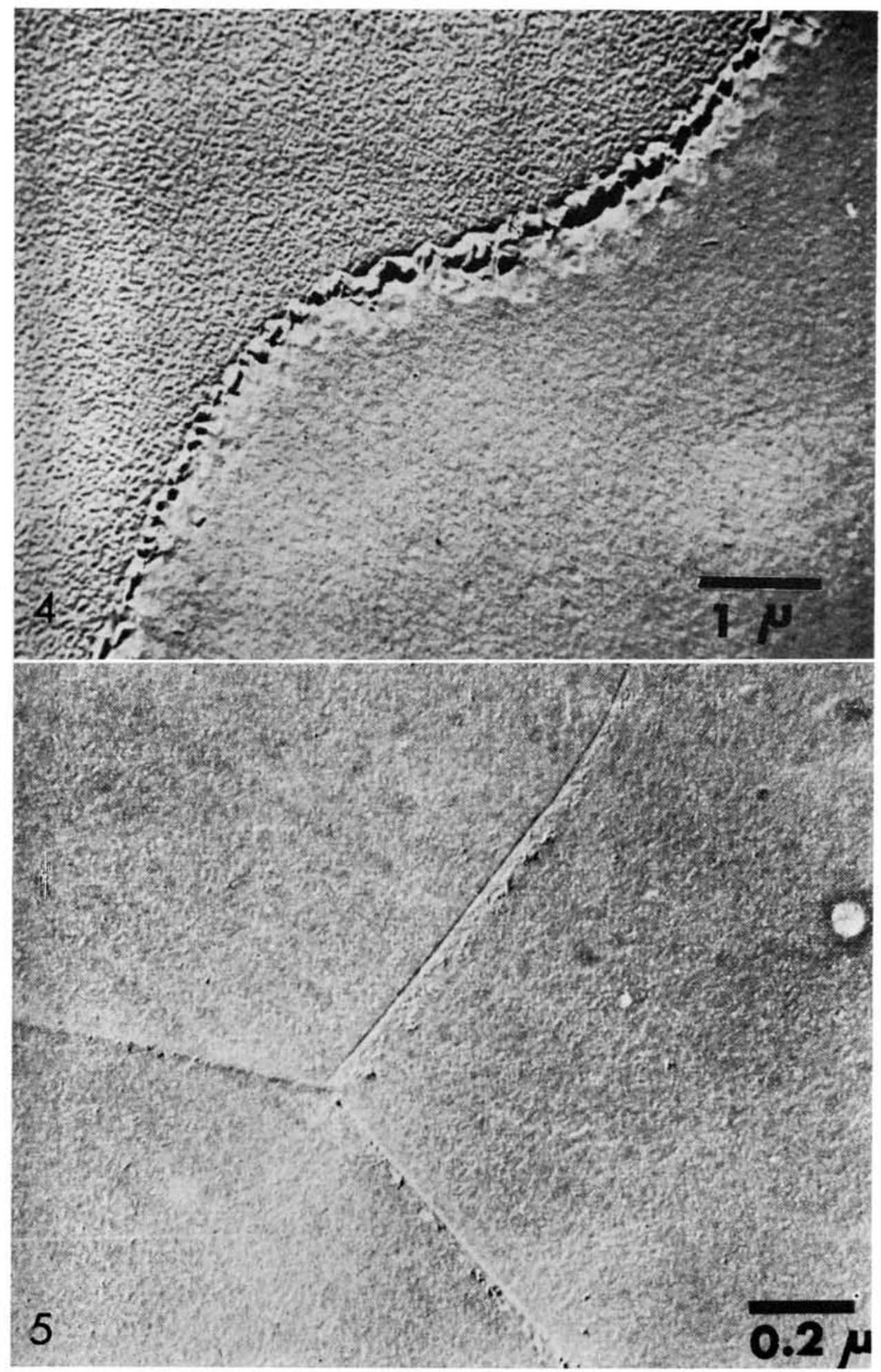

FIG 4.-A portion of the interface shown in Figure 4 (orig mag $\times 65,000$ ).

FIG 5.-Properly heated solder joint showing no diffusion along grain boundaries (orig mag $\times 78,000)$. 
alloy. This distinct demarcation confirmed the finding of previous investigations ${ }^{1}$ that a solder joint could be obtained without diffusion between the solder and the parent alloy. A soldering pit can be seen in Figure 3 near the interface.
The gold alloy along the border of the solder was photographed at $\times 13,000$, (Fig 4). A three-sided grain structure formation was observed (Fig 5). No diffusion was seen along the grain boundaries.

A structure of special geometric configur-

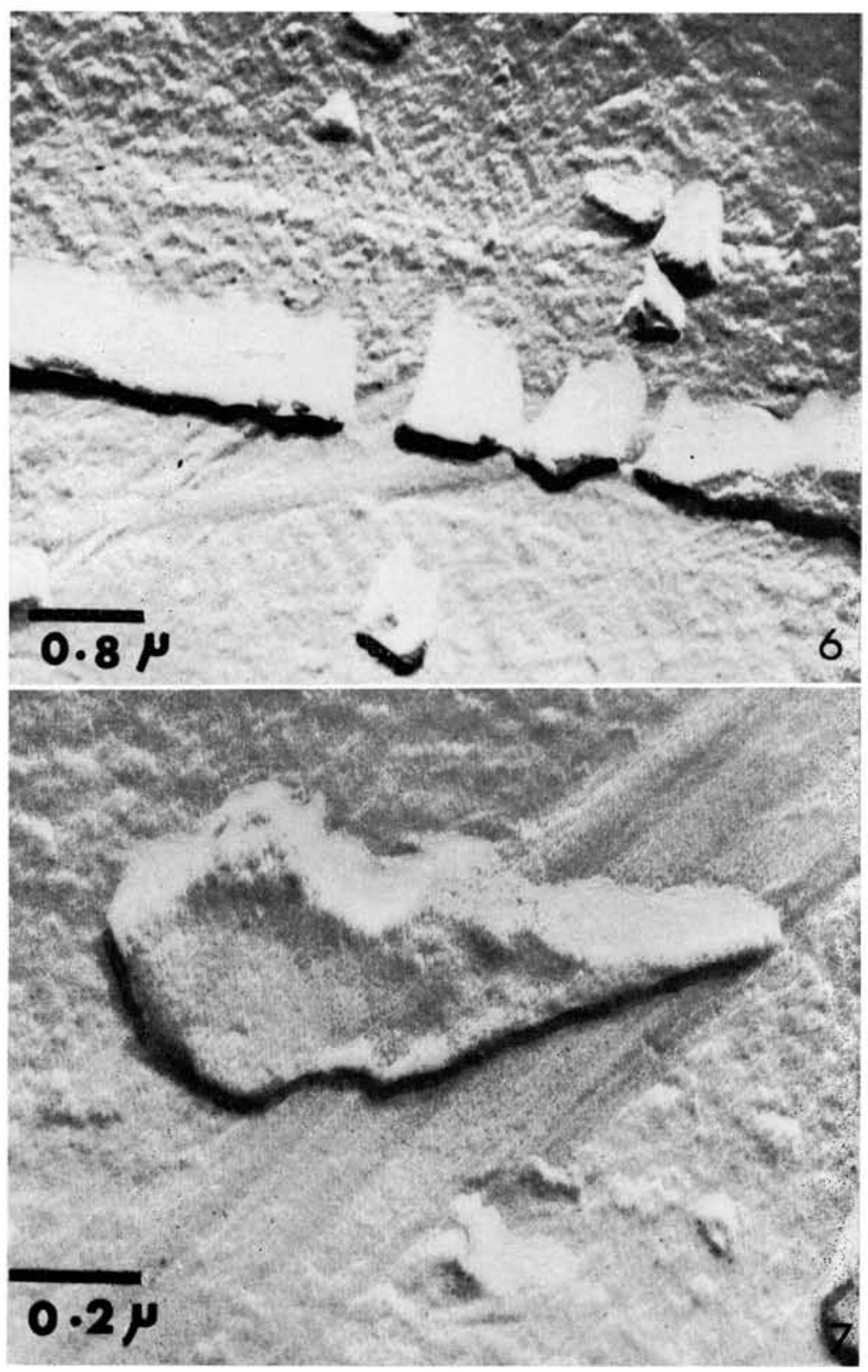

FIG 6.-Assumed oxide formation along interface (orig mag $\times 27,000$ ).

Fig 7.-Assumed oxide particle shown in Figure 6 (orig mag $\times 93,000$ ). 


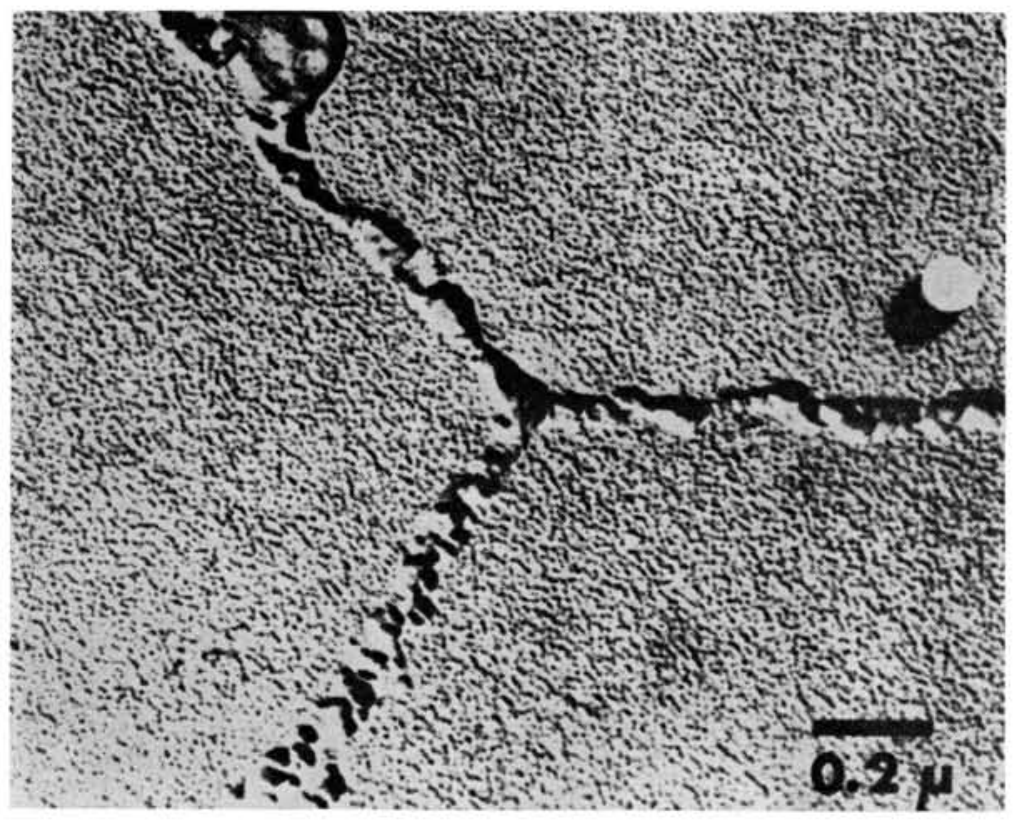

FIG 8.-Overheated solder joint showing partial diffusion of the solder along grain boundaries (orig mag $\times 78,000$ ).

ation is shown in Figures 6 and 7. According to the theories of surface energy, this structure was not a solder pit, but rather an oxide formation at the gold-solder interface. Oxides are usually resistant to etching; the ultrastructure of these assumed oxides resembles that of the parent alloy (Fig 7). Improper fluxing may have been the reason for this oxide formation.

Overheated Gold Soldered Joint.Some diffusion along the grain boundaries was observed when overheating occurred (Fig 8). No distinct interface of solder and parent alloy was seen. When Figure 8 is compared with Figure 5, it can be seen that there is more microporosity in the overheated joint. A greater irregularity of the grains was also observed.

\section{Discussion}

An experimental study ${ }^{10}$ of the decomposition of gypsum investments showed that $\mathrm{CaSO}_{4}$ will decompose when heated to $1,300 \mathrm{C}$ or above, and that the reduction of calcium sulfate by carbon takes place rapidly above $700 \mathrm{C}$, releasing calcium sulfide and sulfur dioxide:

$$
\begin{aligned}
\mathrm{CaSO}_{4}+4 \mathrm{C} & \rightarrow \mathrm{CaS}+4 \mathrm{CO} \\
3 \mathrm{CaSO}_{4}+\mathrm{CaS} & \rightarrow 4 \mathrm{CaO}+4 \mathrm{SO}_{2}
\end{aligned}
$$

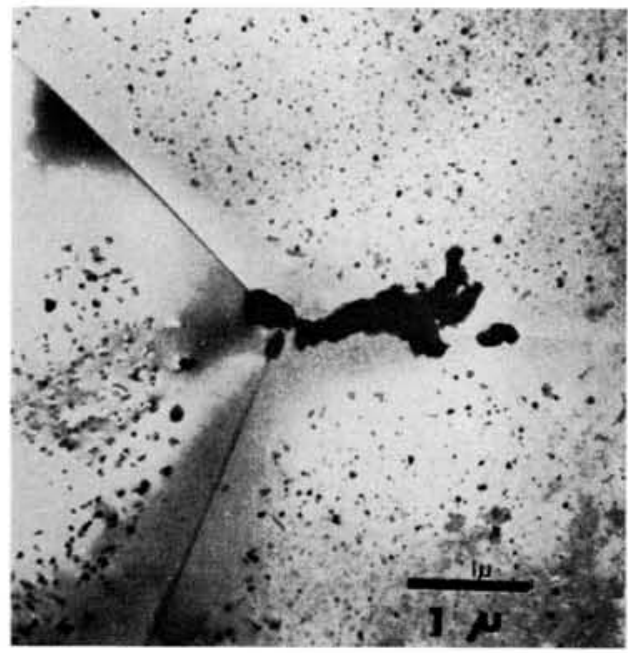

FIG 9.-Evidence of oxide formation and microporosity in overheated solder joints (orig mag $\times 69,000)$.

These products contaminate the gold castings and make them brittle, ${ }^{9,11,12}$ and may also cause microporosities (Fig 9). In Figure 9 , there can also be seen some evidence of microporosity and oxide formation that may have resulted from the overheating of 
TABLE 1

TYPICAL COMPOSITION

\begin{tabular}{|c|c|c|c|c|c|c|c|}
\hline \multirow[b]{2}{*}{ Material } & \multicolumn{7}{|c|}{ Weight $(\%)$} \\
\hline & Gold & Copper & Silver & Palladium & Platinum & Zine & Tin \\
\hline Alloy & 70.0 & 10.0 & 15.0 & 3.0 & 1.0 & 1.0 & \\
\hline Solder & 65.0 & 13.1 & 16.3 & $\ldots$ & $\ldots$ & 3.9 & 1.7 \\
\hline
\end{tabular}

tin and zinc in the solder, together with an increased amount of copper which, during overheating, tends to oxidize. The configuration of these structures, which are assumed to be oxides, resembles those in Figures 6 and 7.

Complete diffusion, which is indicated by the absence of interface, may take place between the parent alloy and the solder under extremely high temperatures (Fig 10). From a theoretical point of view, diffusion by itself should not produce an inferior joint. ${ }^{13,14}$ To achieve complete diffusion, however, extremely high temperatures should be employed. Unfortunately, under such circumstances, pitting of the joint, microporosity, and oxide formation appear to be unavoidable. These factors in turn will cause inferior physical properties of the soldered joint in terms of modern concepts of metallurgy.

\section{Conclusions}

No diffusion of the solder was observed in the properly heated soldered joint. Pronounced diffusion, however, occurred in the overheated joint along the grain boundaries of the parent alloy.

There was oxide formation in both the properly heated and overheated joints. It was more pronounced, however, in the latter. Properly used fluxes could prevent oxidation.

Greater microporosity, which may result in reduction of strength and ductility of the soldered joint, was observed in the overheated joints. Microporosity is contraindicated in oral restorations since it may result in corrosion and discoloration in the mouth.

Theoretically, complete diffusion between the solder and the parent alloy should result in a superior metallurgical joint; however,

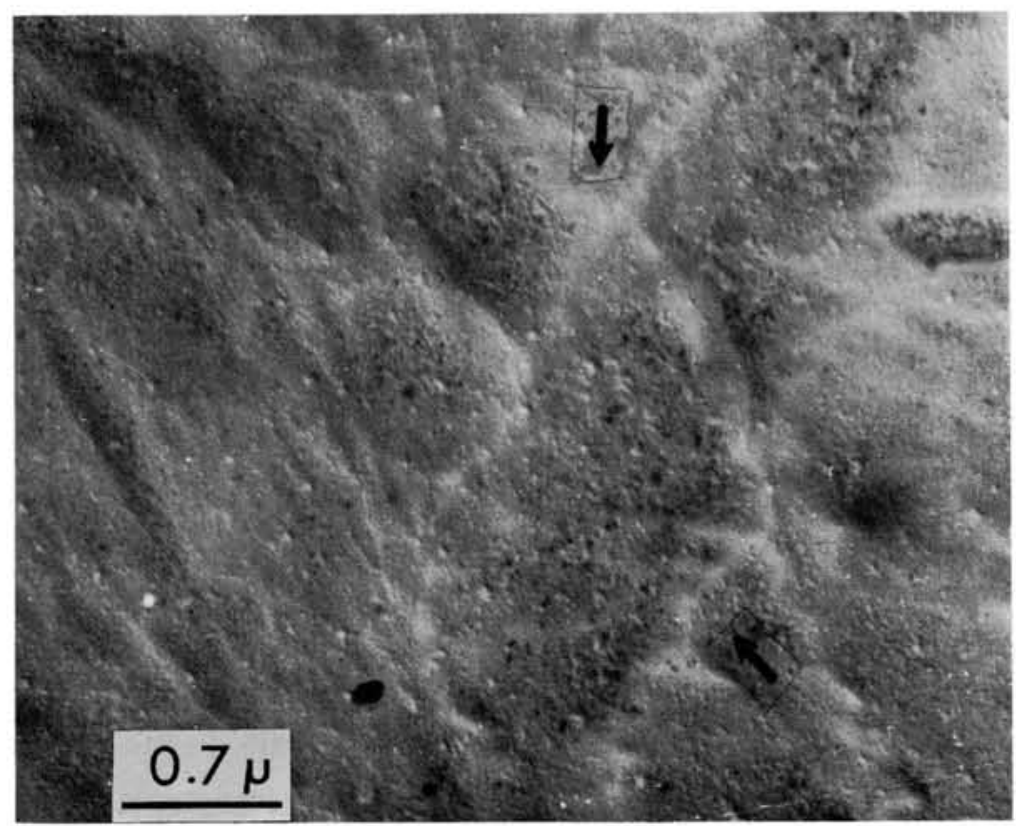

FIG 10.-Complete diffusion of the solder and the parent alloy (orig mag $\times 93,000)$. 
such a joint is not produced by dental gold soldering procedures because of the unavoidable microporosity and oxide formation.

\section{References}

1. Ryge, G.: Dental Soldering Procedures, Dent Clin N Amer 1958, pp 747-757.

2. O'Brien, W.J., and RYge, G.: Contact Angles of Drops of Enamel on Metals, $J$ Prosth Dent 15:1094-1110, 1965.

3. Peyton, F.A.: Restorative Dental Materials, St. Louis: C. V. Mosby Co., 1964, pp 327339.

4. Skinner, E.W., and Phillips, R.W. The Science of Dental Materials, ed 5, Philadelphia: W. B. Saunders Co., 1960, pp 520-527.

5. Brumfield, R.S.: Dental Gold Structures, New York: J. F. Jelenko \& Co., 1953, pp 109-111.

6. The Ney Gold Handbook, Hartford, Conn.: J. M. Ney Co., 1950, pp 16-20.

7. The A. B. Metal Digest, Evanston, Ill.: Buehler Ltd., 1963, vol. 1, no. 1, pp 16-17.
8. WISE, E.M.: Gold, Recovery, Properties and Applications, New York: D. Van Nostrand Co., 1964, pp 234-235; 267; 272-273; 357; 360-362.

9. Gilson, T.D.; Asgar, K.; and Peyton, F.A.: The Quality of Union Formed in Casting Gold to Embedded Attachment Metals, J Prosth Dent 15:464-473, 1965.

10. O'Brien, W.J., and Nielsen, J.P.: Decomposition of Gypsum Investment in the Presence of Carbon, $J$ Dent Res 38:541-547, 1959.

11. Collins, P.F.: Dental Investment Composition and Process, US Patent 1,953,075, April, 1934.

12. Collins, P.F.: Dental Investment Composition and Process, US Patent 2,006,733, July, 1935.

13. GUY, A.G.: Elements of Physical Metallurgy, Addison-Wesley Publishing Co., 1960, pp 418-430.

14. Chalmers, B.: Physical Metallurgy, New York: John Wiley \& Sons, 1959, pp 122-126. 